\title{
O futebol no campo afetivo da história
}

Luiz Carlos Ribeiro*

Resumo: Problematizando a visão racional e pragmática que ainda predomina nas ciências sociais, o presente artigo propõe uma discussão epistemológica para o estudo do futebol como objeto científico. Em síntese, a proposta da apreensão dos sentimentos de afetividade e paixão, como meandros para a compreensão do futebol para além do racional e do pragmático.

Palavras-chave: Teoria da História, História do Futebol, Metodologia.

O futebol, como toda prática social, encontra-se de tal modo imbricado com a sociedade que tomá-lo como objeto de estudo implica em se abrir para possibilidades imensas de abordagens. Os limites desse artigo nos permitem apenas arrolar e tecer rápidos indicativos sobre algumas dessas possibilidades.

A primeira delas nós anunciamos desde o início. Ou seja, o futebol só pode ser abordado na sua complexidade se o compreendermos como um fenômeno social e historicamente produzido. Isso quer dizer que, mesmo quando discutimos táticas e regras, condicionamentos físicos etc., eles sempre deverão ser compreendidos como táticas, regras e condicionamentos socialmente produzidos.

\section{A mitológica dicotomia entre futebol arte e futebol força}

Nesse aspecto, por exemplo, a inesgotável discussão - para além do discurso mitológico - entre o futebol arte (do passado) e o futebol força ou técnico (recente), nos permite uma abordagem crítica. Se submetermos esses momentos às condições objetivas em que o esporte era (e ainda é) praticado, por um lado vamos perceber o quanto a relação arte e força é falsa, se colocada como uma dicotomia simples. Com isso queremos dizer que se essa relação em parte é verdadeira, ela já estava dada nos 30-60, quando supostamente predominava o futebol-arte.

* Doutor em História - Departamento de História - UFPR

Movimento, Porto Alegre, v. 10, n. 3, p.99-111, setembro/dezembro de 2004 
Ver, nesse sentido, a leitura clássica sobre o futebol apolíneo dos europeus e o dionisíaco dos brasileiros, desenvolvida por Gilberto Freyre e que se tornou referência para a definição de um suposto estilo brasileiro de jogar.

Um outro fato é que, a partir do momento em que essa dicotomia passa a ser enfatizada, nos anos setenta, as condições sociais do esporte em geral e do futebol em particular eram outras. O desenvolvimento da medicina esportiva e a valorização econômica com a espetacularização do esporte, não deixaram espaço para o futebol romântico e boêmio que teria existido até a era Pelé, citada de forma nostálgica e pouco crítica como exemplo do chamado futebolarte.

Afirmar o caráter social e histórico do futebol, contudo, não significa ignorar a sua autonomia enquanto campo específico. O seu estudo, ao mesmo tempo em que não pode perder de vista a dimensão social, não pode soterrá-lo de estrutura, a tal ponto que não nos permita perceber a sua dinâmica específica, que sem dúvida não é a das classes sociais, do estado, das religióes, dos sindicatos ou dos partidos políticos.

O método para compreender a dimensão social do futebol, deve partir de uma descrição etnográfica densa, enunciando com o máximo de detalhes a sua dinâmica.

Será o desvelamento das suas regras e da sua experiência cotidiana, como prática social singular do campo esportivo, que nos permitirá contextualizá-lo e percebe-lo na complexa teia da estrutura social.

\section{Possibilidades metodológicas}

Apesar de toda essa riqueza de possibilidades que o estudo sobre o futebol abre para a compreensão da complexidade do social, o tema tem sido pouco explorado no campo científico. Ainda predomina nessa área, a literatura de memorialistas e curiosos que, sem deixar de ter sua importância, produz uma visão permeada de subjetividade acrítica e de reprodução de mitos. O fato é que esse tipo de literatura, na maioria das vezes muito próximo da ficção, é motivado muito mais pela paixão do envolvimento que pelo distanciamento crítico, como deve ser o esforço de todo estudo científico.

A pouca produção científica sobre o futebol, em grande parte deve-se ao preconceito que existe no meio acadêmico. Giulianotti

Movimento, Porto Alegre, v. 10, n. 3, p.99-111, setembro/dezembro de 2004 
atribui esse desprezo ao desdém intelectual à cultura de massas, como se verifica entre os teóricos frankfurtianos, pelo fato dessa cultura "impressionar o povo consumista com a trivialidade de jogar e assistir a jogos". (Giulianotti, 2002, p. 33). Trata-se, na verdade, de uma variável da leitura marxista tradicional que atribui um caráter alienante ao esporte. No limite, marxistas ortodoxos e sua variável frankfurtiana, partem de uma mesma base de raciocínio, qual seja a de que o esporte, enquanto um produto de consumo de massa da sociedade contemporânea, gera a alienação, a falta do discernimento crítico, sendo por isso facilmente manipulado politicamente.

Nessa linha de raciocínio, não é diferente a leitura que Hannah Arendt faz da adesão de milhares de cidadãos aos regimes totalitários europeus. A autora analisa o surgimento das massas como um desvio, resultado da falência da sociedade de classes. Para Arendt, enquanto a classe operária organizava o seu movimento e a burguesa os seus partidos, as massas constituíram-se sem vínculo social e, conseqüentemente, sem qualquer projeto político que lhe conferisse coesão social. (Arendt, 1978, p. 265) Tanto que se refere a essa massa como ralé:

A ralé é fundamentalmente um grupo no qual estão representados resíduos de todas as classes. É isto que torna tão fácil confundir ralé com povo, o qual compreende todas as camadas sociais. Enquanto o povo [...] luta por um sistema realmente representativo, a ralé brada sempre pelo homem forte, pelo grande chefe. Porque a ralé odeia a sociedade da qual é excluída e odeia o parlamento onde não está representada. (Arendt, 1978, p. 164-5)

Desse modo, fundada na tradição marxista que elege o proletariado e a burguesia como as classes fundamentais e as únicas capazes de uma verdadeira consciência de classe, esses intelectuais não conseguem compreender como cidadãos puderam ter aderido a regimes totalitários como o nazi-fascismo. A forma sociológica de analisa-los é pela exclusão: esses indivíduos não expressam a consciência de classe nem do proletariado, nem da burguesia. Partem, esses intelectuais do suposto de que estes - proletariado e burguesia - por pertencerem a uma classe, devem ter coesão social e, conseqüentemente, consciência de classe e projetos políticos definidos.

Trata-se, evidentemente, de uma coesão social atribuída. Uma consciência racional de classe que a Teoria - porque "conhece" as leis da história - atribui a determinados grupos sociais e não suporta a possibilidade de que esses grupos não atuem da forma prevista. Ao se defrontarem com manifestações que não se enquadram

Movimento, Porto Alegre, v. 10, n. 3, p.99-111, setembro/dezembro de 2004 
naquilo que determinam como consciência social de classe, os cientistas sociais preferem o desprezo.

Esta é a leitura que tem predominado no Brasil sobre as classes sociais, desde os anos vinte/trinta. Como não se encontra na sociedade brasileira experiência de classes como o definido pela teoria, afirma-se da sua fragilidade ou mesmo inexistência, como tem ocorrido com as análises sobre classe operária, classes médias, tenentismo e outros recortes sociais. Ver, nesse sentido, as obras em torno da sociologia marxista brasileira dos anos sessenta/setenta: entre outros, Boris Fausto, Octavio Ianni, Francisco Weffort.

No caso europeu, o pensamento marxista não suporta - tanto no plano epistemológico quanto no ideológico - a possibilidade de que a classe trabalhadora alemã aderiu de maneira massiva ao regime nazista e, portanto, não se comportou como classe revolucionária (atributo de sua suposta consciência social) e agiu como massa. Ou como prefere Arendt, como ralé.

É, portanto, em função da camisa-de-força desses paradigmas que o futebol é visto como expressão de uma multidão alienada e alienante, incapaz de qualquer racionalidade, sendo o seu estudo desonroso.

De nosso ponto de vista, essa conclusão incorre em alguns problemas. Primeiro, que as classes sociais são vistas aqui como determinações exteriores e não a partir do seu fazer-se, da experiência própria dos indivíduos que as compõem (Castoriadis, 1982 ; Thompson, 1987). Ou seja, é a Teoria, e não a experiência histórica efetiva dos indivíduos e grupos, que define as classes e o que deve ser as suas consciências sociais, suas "visões de mundo". Como decorrência, reforça a idéia de que os lugares da política e das relações de poder são de tal forma predeterminados que a luta entre as "classes fundamentais" é eleita como o único lugar da história. E, finalmente, impede de perceber que as massas - que tanto desprezam - com certeza estão contidas das chamadas classes fundamentais - proletariado e burguesia -, apenas que a Teoria não permite perceber.

Assim, a questão epistemológica central é que, partindo dessa tradição racionalista do pensamento ocidental, o conhecimento científico não consegue desenvolver ferramentas teóricas que permitam analisar o comportamento dos indivíduos, dos grupos, das classes sociais e das massas. Como afirma o sociólogo francês, Pierre Ansart, ao criticar tal racionalismo, esta "escolha custa o preço de um fracasso". Por esse viés exclusivo

Movimento, Porto Alegre, v. 10, n. 3, p.99-111, setembro/dezembro de 2004 
da racionalidade pragmática das ciências sociais, "é impossível dar conta da experiência dos agentes da história tais como eles a vivenciam ou a sofrem". (Ansart, 1983, p. 7)

Analisando esse desprezo da tradição científica, Norbert Elias e Eric Dunning identificam nos "paradigmas racionalizantes", a redução do "campo de visão" das ciências "a um conjunto comparativamente estreito de atividades sociais", apesar de sua pretensão de tratar a sociedade em todos os seus meandros. (Elias ; Dunning, 1992, p. 15)

Ou seja, para estes autores, as ciências sociais teriam se orientado para o "campo restrito dos aspectos sério e racional da vida, o que teve como efeito que o divertimento, o prazer, o jogo, as emoções e as tendências irracionais e inconscientes do homem e da mulher tivessem merecido escassa atenção no âmbito da teoria e da investigação sociológica" (Elias; Dunning, 1992, p. $16)$.

Inscrito na marginalidade dos campos formais do econômico, do político, do social e do cultural e visto como atividade de lazer e ócio - portanto em oposição ao trabalho, lugar por excelência do fazer humano - , o esporte não se configura como objeto de interesse das ciências para a compreensão do processo social.

De qualquer modo, a perspectiva para o estudo do futebol como tema consistente de pesquisa, começa a romper as barreiras seguras da tradicional academia dos cientistas sociais. A compreensão dessa invasão pode ser percebida a partir de alguns elementos historicamente datados.

Um deles tem sido a forte abertura que as ciências sociais vêm realizando, a partir da chamada crise dos paradigmas, vivida no Brasil mais intensamente a partir dos anos 80. A crítica aos grandes modelos explicadores, anunciada desde os anos 20/30 pela antropologia, pela lingüística e a psicologia, e avançada nos anos 80/90 com a derrocada do socialismo real e as redefinições epistemológicas propostas pela crítica ao estruturalismo marxista ou dos Annales -, exigiu das ciências sociais a busca de novos elementos para a compreensão do social.

Desprovidas da segurança dos modelos, as ciências sociais abriram-se para novos temas e novos objetos, cada vez mais sem restrição.

Movimento, Porto Alegre, v. 10, n. 3, p.99-111, setembro/dezembro de 2004 
Um outro elemento concomitante, é a reestruturação das lutas sociais e a ocorrência sistemática de novos movimentos de massa nos anos 80/90 que, sem mais a segurança dos clássicos modelos explicadores, têm demandado estudos etnográficos mais intensos. Ou seja, diante da ausência da explicação fornecida antes pelo modelo, só tem restado ao cientista social o mergulho na especificidade da experiência, buscando retirar dela não mais a totalidade, mas a alteridade e a relação, produzindo, conseqüentemente, novas referências epistemológicas.

Tem sido assim desde os movimentos sociais urbanos dos anos 60 , até os mais recentes, como por exemplo os hooligans (Giulianotti, 2002), as gangues suburbanas ou as torcidas organizadas de futebol (Da Matta, 1982; Toledo, 1996).

Apesar de direta ou indiretamente relacionada à reestruturação das relações sociais de produção e do conseqüente surgimento do chamado "desemprego estrutural" - a chamada globalização dos anos noventa -, a originalidade dessas análises tem sido o não reducionismo ao social ou ao econômico.

Nesse sentido, um ponto para o qual parecem convergir os diversos estudos sobre os movimentos sociais, urbanos e de massa - aí incluso o futebol - é o que procura romper com a falsa dicotomia entre ações racionais - portanto sérias e dignas de estudo - e as irracionais - relegadas ao campo da excepcionalidade e do excêntrico, e portanto sem nenhum interesse para o estudo do social.

Assim, a busca de referências teóricas e metodológicas para o estudo do futebol, tem necessariamente que passar pela interdisciplinaridade. Nesse sentido, a obra de Norbert Elias sobre o processo civilizador e suas análises produzidas sobre o esporte, em parceria com Eric Dunning, nos parece um bom ponto de partida.

Um bom exemplo dessa relação tensa entre equilíbrio e desequilíbrio, entre a parte rígida e a flexível, é o drible, considerado um dos momentos mágicos no futebol.

O drible, ao mesmo tempo em que é a expressão da individualidade e da indeterminação, está contido na regra e é visto como a expressão maior do esporte. Tanto quanto o gol que finaliza um esforço, o drible faz parte daquele momento mágico que antecipa o êxtase. É um dos momentos maiores da excitação no futebol. Porém, se ele não tem limite de acordo com as regras - pois, por princípio é o oposto do choque e da violência -, quando praticado em excesso pode tanto fragilizar sua própria equipe, quanto gerar um sentimento de humilhação no adversário e degenerar em violência. É clássico o

Movimento, Porto Alegre, v. 10, n. 3, p.99-111, setembro/dezembro de 2004 
exemplo ocorrido no jogo entre Palmeiras e Corinthians, que disputavam a final do Campeonato Paulista de 1999. Próximo do final da partida, que se encontrava empatada e por conseqüencia dava o campeonato ao Corinthians, o jogador corinthiano Edilson realizou uma "embaixada" na lateral do campo, num claro sinal de menosprezo e humilhação ao adversário. A reação dos jogadores adversários foi iniciar uma pancadaria que se generalizou, envolvendo jogadores, dirigentes e equipe técnica, obrigando o juiz a encerrar a partida aos 31 minutos do segundo tempo. O lateral Júnior, do Palmeiras, um dos primeiros a revidar a provocação de Edílson, assim se manifestou à imprensa: "Ele não teve uma postura de homem. Entrei duro, para tentar quebrá-lo. Ele nos humilhou e isso não se faz. Não o perdôo." O eficiente controle da bola (a embaixada) que deveria ser parte do espetáculo, tornou-se fator de desequilíbrio, flexibilizando a parte rígida do futebol.

\section{O futebol como uma dimensão afetiva da política}

Esses questionamentos que desenvolvemos com relação a dificuldade - e, em alguns casos até mesmo a recusa - das ciências sociais tratarem o futebol como um tema socialmente relevante, igualmente ocorre com os temas tradicionais, tal como classes sociais, partidos políticos, Estado etc.

Ou seja, os mesmos paradigmas que soterram o conhecimento científico e o engessam para a abertura a novas abordagens, também agem sobre os temas convencionais. Referindo-se aos estudos da política, Pierre Ansart coloca a extensão do problema da seguinte maneira:

A dimensão afetiva da vida política, os sentimentos comuns, as paixões coletivas que participam das práticas políticas constituem um domínio de difícil conhecimento, um desafio, portanto. Como compreender e explicar a intensidade de uma emoção coletiva e suas conseqüências, a persistência de um apego, a violência de um amor ou de ódios políticos? (Ansart, 1983, p. 7)

Para esse autor, "a recusa em enfrentar essas dificuldades tem sido a solução mais comum", na medida em que o racionalismo cienticista eliminou as experiências cotidianas de seu campo de observação, "para somente reter da 'realidade' política aquilo que pode ser traduzido racionalmente", resultando disso o fracasso do conhecimento (Ansart, 1983, p. 7).

De maneira diversa dos intelectuais de matriz positivista e marxista, Ansart afirma a necessidade de se redescobrir as

Movimento, Porto Alegre, v. 10, n. 3, p.99-111, setembro/dezembro de 2004 
paixões políticas, pois "é preciso pesquisar como as paixões, as emoções, os sentimentos acompanham e sustentam as práticas políticas particulares e através de quais procedimentos, de quais agentes e com quais conseqüências" (Ansart, 1983, p. 8).

Ou seja, antes de partir dos grandes esquemas explicadores que nada mais são do que paradigmas; mais do que procurar compreender os processos a partir dessas racionalizações, devemos nos abrir para a afetividade de lugares inusitados, impedidos que são de serem visitados ou conhecidos pelo risco que trazem à Teoria. E procurar verificar como esses elementos emotivos "intervém na renovação ou nas mutações" da sensibilidade coletiva. (Ansart, 1983, p. 8)

E o futebol é, por excelência, um desses lugares em que a afetividade da política se manifesta para além da racionalidade pragmática. Fortemente contido de paixão - individual e coletiva - o futebol não se prende exclusivamente às determinações de classes, na medida em que, tomadas de forma clássica, elas são excessivamente redutoras. Nesse sentido, a dimensão afetiva da vida esportiva é também marcada pela paixão e pelo ressentimento. É, portanto, o lugar da "inconsciência", no sentido oposto daquela consciência racional determinada e imposta de cima e de fora dos sujeitos e dos grupos. É um espaço privilegiado do inconsciente coletivo, dos indivíduos e das massas. O lugar por excelência da indeterminação.

Como experiência afetiva da política, o estudo do futebol permite desenvolver o rompimento da "nítida separação entre razão e paixão e, mais do que isso, o pressuposto do predomínio da primeira sobre a segunda, como forma de conduta do mundo civilizado", como propõe hoje um renovado debate da história política. (Bresciani, 2002, p. 8)

Nesse sentido, o futebol expressa os sentimentos mais significativos da organização humana, que é o da identidade e o de pertencimento.

Seja com relação ao clube ou ao selecionado nacional, manifesta-se um sentimento de afetividade e de pertencimento que dá sentido não apenas à instituição futebolística, mas ao lugar a que ela se encontra vinculada.

A questão que se coloca é, a partir do reconhecimento dos limites da dicotomia razão e paixão e da valorização do estudo do futebol como lugar especial para essa reflexão, como efetiválo?

Movimento, Porto Alegre, v. 10, n. 3, p.99-111, setembro/dezembro de 2004 
Autores como Elias e Bourdieu propõem a descrição detalhada dos elementos e dos comportamentos do objeto estudado - no caso, o futebol -, no sentido de percebê-lo, antes de tudo, na sua especificidade. Elias denominou a estrutura desse objeto de configuração, Bourdieu denominou de campo.

A descrição das funções e dos atores, permite apreender a ação subjetiva de indivíduos, seus sentimentos e suas forças de envolvimento.

Assim, apenas como exemplo, conhecer o futebol brasileiro dos anos 50/70, exige um estudo biográfico renovado de personagens como Garrincha ou Pelé ou, de outra forma, estudar como se dava a formação de jogadores à época. Do mesmo modo, conhecer a experiência da "democracia corinthiana", do início dos anos 80, exige igualmente uma análise da conjuntura política, da estrutura organizativa do clube, bem como da postura individual de jogadores como Sócrates, Wladimir ou Afonsinho.

Esse exercício com certeza nos coloca perante um outro tipo de problema, paradoxal em nossa análise. Ou seja, estaremos diante da necessidade de trabalharmos com uma documentação primária eivada de subjetividades. Como já destacamos nas primeiras linhas desse artigo, trata-se de um material que, pela sua subjetividade, pelo envolvimento emocional e autonomia dos autores, manifestase descompromissado com a realidade mas, paradoxalmente, encontra-se aí a sua riqueza.

São crônicas esportivas (escritas tanto por jornalistas especializados quanto por curiosos e memorialistas), memórias e relatos onde a interpretação personalizada (geralmente na primeira pessoa) é a principal característica.

Nelson Rodrigues, um dos grandes cronistas esportivos do Brasil, defendia com veemência a imaginação no lugar da objetividade dos fatos. Em artigo ontológico publicado em 1956, afirmava que o cronista esportivo deveria "retocar o fato, transfigurá-lo, dramatiza-lo". Deveria dar à "espúria e chata realidade um sopro de fantasia". Para Nelson, "o jornalista que tem o culto do fato é profissionalmente um fracassado" (Apud TOLEDO, 2002, p. 164).

Mais recentemente Matinas Suzuki emitiu uma opinião muito próxima desta, na apresentação que fez no livro de memórias sobre as copas de 1950 e 1954:

Movimento, Porto Alegre, v. 10, n. 3, p.99-111, setembro/dezembro de 2004 
Uma das coisas mais cativantes no futebol é a memória afetiva. Um goleiro ou um centroavante que vimos na infância, um gol, um drible, a camisa de um time... enfim, a nossa relação com o futebol é intermediada pelo evocar dos primeiros alumbramentos com a bola.

Pois bem, este livro participa do inesgotável exercício do prazer que éa narrativa da memória afetiva futebolística [...].

A história da literatura já demonstrou que a narrativa só tem interesse para o outro se ela se fundamentar em uma profunda experiência pessoal. [...] dada pela memória afetiva (Suzuki Júnior, 1994).

Portanto, a "memória afetiva" de Matinas Suzuki Jr, não é diferente do "acréscimo de imaginação", proposto por Nélson Rodrigues à crônica. Logo, é como um gênero literário - ficção - que devemos tratar estas crônicas e as memórias como produtos que possuem a liberdade da criação.

Nesse sentido, portanto, nos encontramos diante de um paradoxo. Por um lado, este artigo tem a intenção de propor uma metodologia para um estudo científico do futebol, ou seja um estudo que estabeleça com a realidade e com a verdade uma relação crítica. Por outro, para compreendermos o futebol como um fenômeno de massa, e não reduzi-lo às leituras pragmáticas e racionalistas, necessitamos nos abrir para abordagens subjetivas (logo inseguras e cheias de armadilhas), tais como uma "sociologia das afetividades" e a produção ficcional, como a crônica esportiva. Ou seja, se não podemos confundir ficção com realidade, não podemos aprisionar nosso objeto de estudo a uma formalidade que anule a sua indeterminação, pois é nesse "vôo cego" que se encontra grande parte do seu sentido.

A literatura, ao não ter compromisso com a realidade - pois é obra da imaginação de seu autor -, é livre para nos dizer muito mais que o discurso convencional. "Sendo um produto do desejo, seu compromisso é maior com a fantasia do que com a realidade" (Sevcenko, 1983, p. 20). Com essa liberdade, a obra de ficção fala ao historiador "sobre as possibilidades que não vingaram, sobre os planos que não se concretizaram" (Sevcenko, 1983, p. 20).

De todo o modo, o cronista, mesmo quando dá toda vazão criativa à sua memória afetiva, não deixa de ser um homem de seu tempo. Portanto a sua criação não possui uma total liberdade. Ela expressa uma leitura original e livre de sua experiência efetiva, individual e social.

Movimento, Porto Alegre, v. 10, n. 3, p.99-111, setembro/dezembro de 2004 


\section{Conclusão}

Como é possível observar, neste esboço metodológico de tratar o futebol como objeto de pesquisa, optamos por propor mais um desafio de novas abordagens do que seguir o receituário corrente nas ciências humanas. Ao definirmos o futebol como um fenômeno de massa e indicarmos nessa característica uma possibilidade de fazermos frente à visão negativa que o conhecimento científico racional, positivista e marxista, tem do futebol - o caráter de ralé, de lumpen e de inconsciência social -, longe de nós propormos uma resposta ao problema. Apenas problematizamos a forma como a ciência analisa os fenômenos culturais de massa e sistematizamos a hipótese - a partir de alguns autores inovadores -, de explorar a "irracionalidade" e a "ausência de consciência social" desses movimentos de massa.

Essa irracionalidade e inconsistência de coesão social, atribuída às massas - como as que se reúnem em torno do futebol - é resultado do excessivo apego dos intelectuais aos seus paradigmas, produzindo, com isso o preconceito científico e político para com as manifestações populares e de massa.

Mas como dissemos no início, os limites desse artigo e, acrescentaria, de nossa capacidade de dar respostas aos nossos próprios desafios, nos permitem apenas arrolar e tecer indicativos sobre algumas dessas possibilidades. Espero que pelo isso tenhamos feito com alguma clareza.

\section{El fútbol en lo campo afectivo de la historia}

Resumen: Al problematizar la visión racional y pragmática que aún predomina en las ciencias sociales, el presente trabajo propone una discusión epistemológica para el estudio del fútbol como objeto científico. En síntesis, la propuesta de la aprehensión de los sentimientos de afectividad y pasión, como meandros para la comprensión del fútbol para allá de lo racional y lo pragmático.

Palabras-clave: Historia da la Teoría, Historia del Fútbol, Metodología.

Movimento, Porto Alegre, v. 10, n. 3, p.99-111, setembro/dezembro de 2004 


\section{Soccer in the field affecttive of the history}

Abstract: By revisiting the rational and pragmatic vision that is still prevalent in the social sciences, this paper proposes an epistemological discussion over the study of soccer as a scientific object. In short, it's a proposal to grasp the feelings of affectivity and passion, as a way to understand football beyond the rational and the pragmatic.

Keywords: History's Theory, Soccer's history, Methodology.

\section{Referências}

ANSART, Pierre. La gestion des passions politiques. Lausanne (Suisse): Editions L'Age d'Homme, 1983.

ARENDT, Hannah. O sistema totalitário. Lisboa: Dom Quixote, 1978. BOURDIEU, Pierre. Coisas ditas. São Paulo: Brasiliense, 1990.

. Questões de sociologia. Rio de Janeiro: Marco Zero, 1983.

BRESCIANNI, Stella. Apresentação. In: SEIXAS, Jacy ; BRESCIANNI, Stella ; BREPOHL, Marion (Orgs.) Razão e paixão na política. Brasília: Editora UNB, 2002, p.7-11.

CASTORIADIS, Cornelius. A instituição imaginária da sociedade. $3^{\mathrm{a}}$ ed. Rio de Janeiro: Paz e terra, 1982

CHARTIER, Roger. A história cultural. Entre práticas e representações. Lisboa: Difel, 1990

DA MATTA, Roberto (Org.) Universo do futebol. Rio de Janeiro: Pinakotheke, 1982.

ELIAS, Norbert ; DUNNING, Eric. A busca da excitação. Lisboa: Difel, 1992.

ELIAS, Norbert. A sociedade dos indivíduos. Rio de Janeiro: Jorge Zahar Editores, 1993.

. Introdução à sociologia. São Paulo: Edições 70, 1969.

O processo civilizador. Rio de Janeiro, Jorge Zahar Editores, 1994. GIULIANOTTI, Richard Sociologia do futebol. Dimensões históricas e socioculturais do esporte das multidões. São Paulo: Nova Alexandria, 2002.

Costumes em comum. Estudos sobre a cultura popular tradicional. São Paulo: Companhia das Letras, 1998.

SEVCENKO, Literatura como missão. Tensões sociais e criação cultura na Primeira República. São Paulo: Brasiliense, 1983.

SUZUKI JR, Matinas. Apresentação. In: NOGUEIRA, Armando et. al. A copa que ninguém viu e a que não queremos lembrar. São Paulo: Cia das Letras, 1994.

THOMPSON, E. P. A formação da classe operária. 3 volumes. Rio de Janeiro: Paz e Terra, 1987.

Movimento, Porto Alegre, v. 10, n. 3, p.99-111, setembro/dezembro de 2004 
TOLEDO Luiz Henrique. Lógicas no futebol. São Paulo: Hucitec/Fapesp, 2002. TOLEDO Luiz Henrique. Torcidas organizadas de futebol. Campinas: Autores Associados/Anpocs, 1996.

Luiz Carlos Ribeiro Departamento de História - UFPR Rua Gal. Carneiro, 460 - 60 and - Centro Curitiba - PR CEP: 80060-150 ribeiro@ufpr.br

Movimento, Porto Alegre, v. 10, n. 3, p.99-111, setembro/dezembro de 2004 